\title{
Characterization of TiAlV Films Prepared by Vacuum Arc Deposition: Effect of Substrate Temperature
}

\author{
B. AbDallah ${ }^{a, *}$, O. MrAD $^{b}$ And I.M. Ismail ${ }^{b}$ \\ ${ }^{a}$ Atomic Energy Commission, Department of Physics, P.O. Box 6091, Damascus, Syria \\ ${ }^{b}$ Atomic Energy Commission, Department of Chemistry, P.O. Box 6091, Damascus, Syria
}

(Received October 13, 2011; in final form October 14, 2012)

Three TiAlV films have been prepared by vacuum arc discharge technique at different substrate temperatures $\left(50,300\right.$, and $\left.400{ }^{\circ} \mathrm{C}\right)$. The depositions were carried out from aluminum, vanadium and titanium elemental targets. The temperature effects on the crystalline quality and texture have been investigated by means of X-ray diffraction. Two phases have been identified and the grain size has been found to increase with temperature. The composition of the films has been determined by proton induced X-ray emission technique. The Ti ratio was found to increase with temperature. The microhardness, measured by the Vickers indentation method was found to decrease with temperature. X-ray photoelectron spectroscopy was used to study the chemical composition of the passive layer formed on the films by analyzing high resolution spectra of $\mathrm{Al} 2 p$, Ti $2 p$ and $\mathrm{V} 2 p$. This layer was mainly composed of $\mathrm{TiO}_{2}$ with a small participation of other oxidation and metallic states of $\mathrm{Ti}, \mathrm{Al}$ and $\mathrm{V}$.

DOI: $10.12693 /$ APhysPolA.123.76

PACS: 68.55.-a, 87.85.jf

\section{Introduction}

Due to its interesting chemical and mechanical properties, titanium alloy is widely used in many applications [1-4]. One particular alloy, the Ti-6Al-4V, has the best performance among the different grades of titanium. The pure titanium is a monophase, physiologically inert, and non-toxic metal. Ternary titanium alloys containing $\mathrm{Al}$ and $\mathrm{V}$ or $\mathrm{Nb}$ exhibit $\alpha$ and $\beta$ phases structure that has attractive mechanical properties, high wear resistance, hardness, tenacity, resistance to fatigue and high corrosion resistance [5-9] besides having a low density, which makes it a good candidate in the aeronautics industry. In addition, this alloy has an excellent biocompatibility permitting its use in the fabrication of medical implants $[4,10]$.

It is critical from the biocompatibility point of view to understand the surface properties of the alloy. The formation of passive oxide layer $\left(\mathrm{TiO}_{2}\right)$ has the potential to stop the corrosion by reducing the electronic exchange process. Moreover, this layer is chemically stable and can be renewed quickly after each degradation [11].

It is also important to study the microhardness of the films. Many factors could affect it such as $\mathrm{TiO}_{2}$ phase, defect density, stoichiometry, preferred orientation, residual stress, $\alpha / \beta$ phases and grain size [12].

Titanium alloys can be produced by chemical vapor deposition (CVD) or physical vapor deposition (PVD) such as rf-dc sputtering [13-15] and flash evaporation [16]. Although it is not frequently used in this domain, the vacuum arc discharges is an attractive method owing to its high efficiency, control of composition and structure of the films, and high adhesion forces between film and its substrate. It can also produce ions of higher ki-

*corresponding author; e-mail: pscientific@aec.org.sy netic energies (up to $150 \mathrm{eV}$ ) [17, 18]. This results in the formation of a denser film and reducing surface defects, such as voids and columnar growth. While the vacuum arc discharge is normally employed to obtain nitride or oxide films, to our knowledge nobody prepared this alloy (TiAlV) using industrial vacuum arc. Therefore, we aimed to prepare TiAlV alloys starting from elemental targets and using this technique.

In this work, three TiAlV films have been deposited on Si substrates by vacuum arc discharge method with three different temperature conditions. The crystallographic properties of the films were studied by X-ray diffraction (XRD) technique. X-ray photoelectron spectroscopy (XPS) was used to investigate the passive layer formed at the surface. The microhardness was investigated using the Vickers method. In addition, the elemental composition of the films was obtained by proton induced X-ray emission (PIXE) and energy dispersive $\mathrm{X}$-ray (EDX) analysis techniques.

\section{Experimental details}

The films were prepared by vacuum arc deposition using a V-1000 "U" system from pure aluminum, vanadium, and two titanium elemental targets used in four independent arc sources of metallic plasma (Fig. 1). The films were deposited on a $\mathrm{Si}(100)$ substrate within an argon discharge for $15 \mathrm{~min}$. The residual pressure was lower than $3 \times 10^{-6}$ Torr, and the working pressure was about $5 \times 10^{-3}$ Torr. The substrate rotated continuously around the vertical central axis. The substrate was not biased (floating). During deposition, the arc current was maintained at $100 \mathrm{~A}, 80 \mathrm{~A}$ and $90 \mathrm{~A}$ for $\mathrm{Ti}, \mathrm{Al}$, and $\mathrm{V}$ targets, respectively. Three films were prepared under the same conditions but with different substrate temperatures $\left(50{ }^{\circ} \mathrm{C}, 300^{\circ} \mathrm{C}\right.$, and $\left.400{ }^{\circ} \mathrm{C}\right)$. 


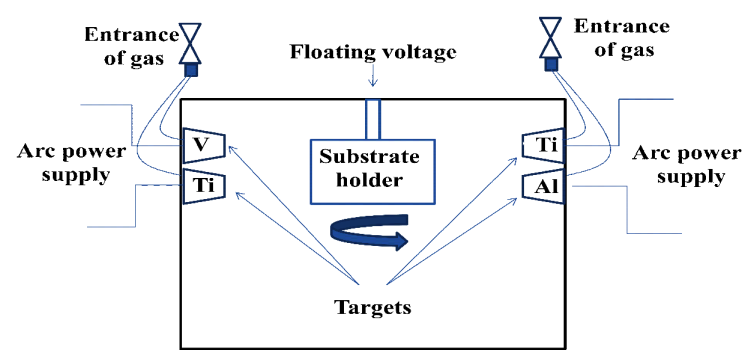

Fig. 1. The vacuum arc discharge system used in the deposition.

The crystallographic properties of the prepared films were studied by XRD (Stoe StadiP Transmission X-ray diffractometer). Although that transmission electron microscopy (TEM) measurements could provide a more clear insight of the grain size, but it is fair enough to use Scherrer's formula to follow the variation of the averaged grain size with the substrate temperature. Films thicknesses were obtained with a Tescan Vega II XMU scanning electron microscope (SEM). EDX was used for determining the elemental composition of the prepared samples.

The elemental composition of the films was measured using the PIXE technique. The measurements were performed using $2 \mathrm{MeV}$ proton beam produced from the 3 MV HVEETM tandem accelerator [19]. Pure Ti, Al, $\mathrm{V}$ and Si reference materials have been used to validate and calibrate the PIXE measurements.

The microhardness has been measured using the Vickers technique with a pyramidal diamond indenter and under a loading force varied from 15 to 75 gram force $(\mathrm{gF})$. The loading time was fixed at $15 \mathrm{~s}$. The load values were chosen carefully after a series of experiences and the values were close to that found in literatures applied on similar hard alloys. SEM was used to determine the dimensions of the indentation. The microhardness values are the average of three measurements.

The XPS analyses were performed using the SPECS $\mathrm{UHV} / \mathrm{XPS} / \mathrm{AES}$ system with a hemispherical energy analyzer. The monochromated $\mathrm{Al} K_{\alpha} \mathrm{X}$-ray $(1486.6 \mathrm{eV})$ is used as the excitation source and is operated at $250 \mathrm{~W}$. High resolution spectra of the $\mathrm{Al} 2 p$, Ti $2 p$ and $\mathrm{V} 2 p$ peaks are treated and deconvoluted, with CasaXPS version 2.3.16 Dev52, using a non-linear least-squares method with a Gaussian/Lorentzian peak shape GL(30) and the background was subtracted using the Shirley method $[20,21]$.

\section{Results and discussion}

\subsection{Structural characterization $(S E M+X R D)$}

The thickness of the films was found to be less than $1 \mu \mathrm{m}$. Figure 2 shows the SEM cross-section image for film prepared at $50^{\circ} \mathrm{C}$. This thickness was about $700 \mathrm{~nm}$.

Figure 3 shows the XRD patterns of the TiAlV films. Two small peaks can be identified and associated to

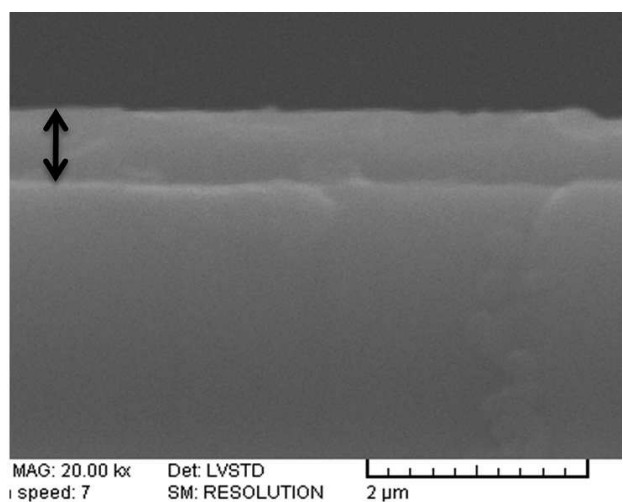

Fig. 2. SEM Cross-section image for film prepared at $50{ }^{\circ} \mathrm{C}$.

$\alpha$-phase of $\operatorname{Ti}(100)$ at $35.2^{\circ}$ and $\alpha$-phase of $\operatorname{Ti}(101)$ at $40.15^{\circ}$. The highest intensity peak is asymmetric and can be assigned to $\alpha$-phase of $\operatorname{Ti}(002)$ and $\beta$-phase of $\operatorname{Ti}(110)$ at $38.2^{\circ}$ and $38.4^{\circ}$, respectively. The $\alpha / \beta$ peak was deconvoluted by Gaussian/Lorentzian peak shape and the FWHM of the $\alpha$-phase of $\mathrm{Ti}(002)$ peak was calculated. The grain size was then calculated using Scherrer's formula [22] for the three films.

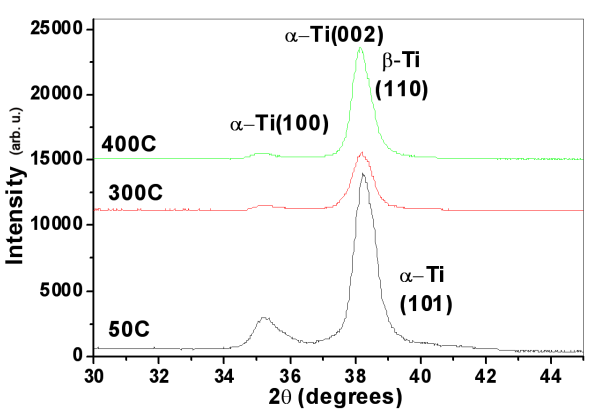

Fig. 3. XRD pattern of the TiAlV films deposited at temperatures $50{ }^{\circ} \mathrm{C}, 300^{\circ} \mathrm{C}$ and $400^{\circ} \mathrm{C}$.

Table I shows that the grain size increased from $13.4 \mathrm{~nm}$ to $17.5 \mathrm{~nm}$ when the substrate temperature increased from $50^{\circ} \mathrm{C}$ to $400^{\circ} \mathrm{C}$. Similar results have been obtained for cubic $\mathrm{ZrN}$ thin film [23] and for $\operatorname{TiN}_{x} \mathrm{O}_{y}$ films [24]. This indicates an improvement of the crystalline quality with the temperature.

\section{TABLE I}

Grain size (nm) as a function of substrate temperatures.

\begin{tabular}{c|c|c|c}
\hline \hline Temperature $\left[{ }^{\circ} \mathrm{C}\right]$ & 50 & 300 & 400 \\
\hline Grain size $[\mathrm{nm}]$ & 13.4 & 15.5 & 17.5
\end{tabular}

\subsection{Micro-hardness measurement}

Table II shows the result of the microhardness measurements for the three films with different loading force 
values. Since the thickness of the films is less than $1 \mu \mathrm{m}$, only the measurements corresponding to smaller loads (15 gF and $25 \mathrm{gF}$ ) are representative of the proper microhardness of the films. Measurements taken with larger load values could be influenced by the substrate hardness. Thus, in the following the measurements corresponding to smaller loads are discussed.

\section{TABLE II}

Vickers microhardness as a function of the loading force for TiAlV films prepared at different temperatures. The results presented here are the mean value of three measurements ( \pm standard deviation $)$

\begin{tabular}{c|c|c|c}
\hline \hline \multirow{2}{*}{$\begin{array}{c}\text { Load force } \\
{[\mathrm{gF}]}\end{array}$} & \multicolumn{3}{|c}{ Micro-hardness [GPa] } \\
\cline { 2 - 4 } & $50^{\circ} \mathrm{C}$ & $300^{\circ} \mathrm{C}$ & $400^{\circ} \mathrm{C}$ \\
\hline 15 & $18.1 \pm 0.3$ & $16.2 \pm 0.1$ & $15.2 \pm 0.2$ \\
25 & $17.2 \pm 0.6$ & $14.8 \pm 0.2$ & $13 \pm 0.1$ \\
50 & $12.3 \pm 0.4$ & $16 \pm 0.4$ & $14 \pm 0.2$ \\
75 & $12.1 \pm 0.4$ & $15 \pm 0.6$ & $13.6 \pm 0.5$
\end{tabular}

The microhardness shows a clear decrease with increasing the temperature. This could be attributed to the increase of oxygen content in the films as follows. It was previously reported [24] that oxygen content in the films prepared by vacuum arc technique decreased with increasing the temperature. On the other hand, the works of Leng et al. [25] on $\mathrm{TiO}_{x}$ and Lui et al. [26] on wollastonite $/ \mathrm{TiO}_{2}$ composite coating suggest an increase of the microhardness with increasing the oxygen content.

The values of the microhardness of the TiAlV films found in the literature varied from $4 \mathrm{GPa}$ to $11 \mathrm{GPa}$ [25, 27-29]. Our measurements are higher than these reported values of about few GPa. This difference could be due, as we believe, to the difference in synthesis techniques. In vacuum arc deposition (we are using), the energy of ionic bombardment is higher $(<150 \mathrm{eV})$ than the sputtering bombardment energy $(<50 \mathrm{eV})$.

It is noteworthy to mention that the larger value of the microhardness corresponds to the smaller grain size (at $50^{\circ} \mathrm{C}$ ). This correlation is in good agreement with a previous study [12] in which authors suggest a relation between the grain size and the microhardness.

\subsection{Composition measurement (EDX + PIXE + XPS)}

The elemental composition of the films has been obtained by means of the PIXE technique. The Ti ratio in the film was calculated as $\mathrm{Ti} /(\mathrm{Ti}+\mathrm{Al}+\mathrm{V})$. Table III demonstrates the values of Ti ratio for the three films. It is clear that the $\mathrm{Ti}$ content increased with the temperature.

\section{TABLE III}

The evaluation of $\mathrm{Ti}$ ratio as a function of the substrate temperature.

\begin{tabular}{c|c|c|c}
\hline \hline & $50{ }^{\circ} \mathrm{C}$ & $300{ }^{\circ} \mathrm{C}$ & $400{ }^{\circ} \mathrm{C}$ \\
\hline Ti ratio & 0.814 & 0.822 & 0.841
\end{tabular}

The stoichiometry of films was found to be sensitive to the substrate temperature. The EDX analysis of the film prepared at $50{ }^{\circ} \mathrm{C}$ showed that the $\mathrm{Ti}$ ratio was about 0.81 . This value is in good agreement with that found by PIXE technique.

The ratio at 0.841 is close to that found by Alfonso et al. whose films were prepared by RF sputtering method starting from a Ti6Al4V target [30].

XPS probes only the very first layers of the surface $(<10 \mathrm{~nm})$ while both PIXE and EDX probe deeper depths (order of microns). For this reason, the stoichiometry is generally obtained using PIXE or EDX.

The chemical composition of the passive layer formed by the exposure of the deposited films to air was studied by means of XPS. No significant change regarding the chemical composition has been observed between the samples. Therefore, we present in Fig. 4 high resolution spectra of Ti $2 p, \mathrm{~V} 2 p$, and Al $2 p$ for one sample.

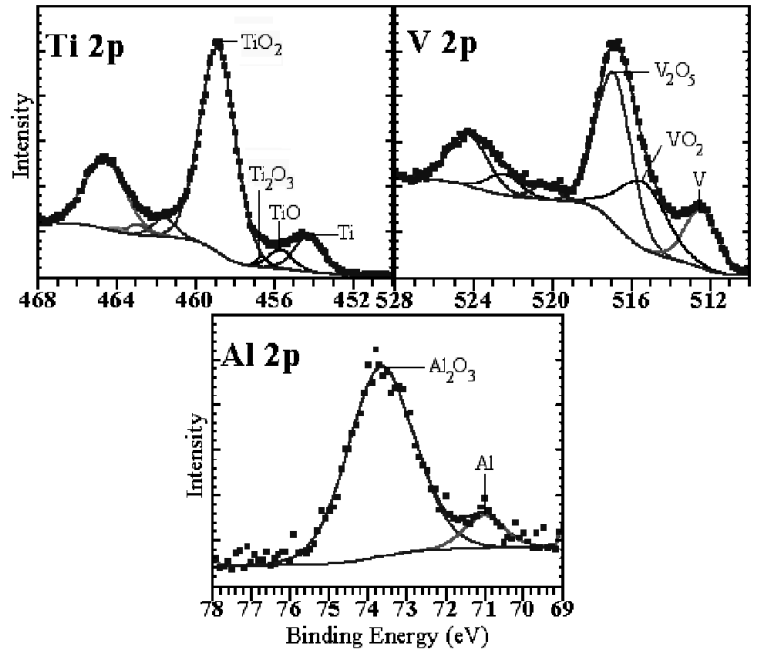

Fig. 4. Deconvolution of high resolution spectra of $\mathrm{Ti}$ $2 p_{3 / 2}, \mathrm{~V} 2 p_{3 / 2}$, and $\mathrm{Al} 2 p_{3 / 2}$.

The deconvolution of $\mathrm{Ti} 2 p_{3 / 2}$ spectrum gives four components that correspond to $\mathrm{TiO}_{2}(\mathrm{BE}=459.2 \mathrm{eV}$, $83 \%)$ [31], $\mathrm{Ti}_{2} \mathrm{O}_{3}(\mathrm{BE}=456.5 \mathrm{eV}, 1 \%)$ [30, 32], $\mathrm{TiO}$ $(\mathrm{BE}=455.4 \mathrm{eV}, 5 \%)[33-35]$ and $\mathrm{Ti}(\mathrm{BE}=454.2 \mathrm{eV}$, $11 \%)[35-37]$. This result is in good agreement with previously reported studies, where $\mathrm{TiO}_{2}$ was also the major component.

$\mathrm{V} 2 p_{3 / 2}$ spectrum has been deconvoluted into three components; $\mathrm{V}_{2} \mathrm{O}_{5}(\mathrm{BE}=516.4 \mathrm{eV}, 51 \%)$ [38-40], $\mathrm{VO}_{2}$ $(\mathrm{BE}=515.4 \mathrm{eV}, 31 \%)[30,38]$ and metallic vanadium $(\mathrm{BE}=512.2 \mathrm{eV}, 18 \%)[41,42]$.

This finding is different from Alfonso et al. [30], where vanadium was mainly composed of the $\mathrm{VO}_{2}$ component and a smaller $\mathrm{V}_{2} \mathrm{O}_{5}$ component; and also different from Milosev et al. [35], where only metallic vanadium was observed on the passive layer surface. In both studies a non-monochromatized Al $K_{\alpha}$ X-ray source has been used. The disagreement in this result is probably due, as we believe, to difference in synthesis techniques.

Al $2 p_{3 / 2}$ spectrum shows a major contribution of $\mathrm{Al}_{2} \mathrm{O}_{3}$ $(\mathrm{BE}=73.6 \mathrm{eV}, 91 \%)$ and a small part of metallic alu- 
minum $(\mathrm{BE}=71.0 \mathrm{eV}, 9 \%)$ [30]. Similar behavior was reported in both studies $[30,35]$.

\section{Conclusion}

In this work, we showed that TiAlV films can be successfully prepared by vacuum arc discharge technique starting from $\mathrm{Ti}, \mathrm{Al}$, and $\mathrm{V}$ elemental targets. The effect of temperature on the composition and crystalline quality has been investigated. The films composition is found to be getting to the standard Ti6Al4V alloy. Increasing the temperature permitted to increase the $\mathrm{Ti}$ ratio and to enhance the texture of the films. The microhardness of the films was found to decrease with the temperature and to be slightly larger than literature values. XPS study proved that the thin passive layer is composed mainly of $\mathrm{TiO}_{2}$. The investigation of corrosion in such films is necessary and it will be the subject of a future work.

\section{Acknowledgments}

The authors would like to thank Prof. Dr. I. Othman (the Director General of the Atomic Energy Commission of Syria) and Prof. Dr. T. Yassin (head of chemistry department) for their encouragement. Thanks are due to Dr. S. Al-Khawaja, Dr. A. Alkhawwam and M.A. Kharroub for assistance as well.

\section{References}

[1] I. Gurrappa, Mater. Charact. 51, 131 (2003).

[2] M. Yamada, Mater. Sci. Eng. A 213, 8 (1996).

[3] I.V. Gorynin, Mater. Sci. Eng. A 263, 112 (1999).

[4] A.C.L. Faria, R.C.S. Rodrigues, A.P.R.A. Claro, M.d.G.C. de Mattos, R.F. Ribeiro, $\square$ J. Mech. Behav. Biomed. Mater. 4, 1873 (2011).

[5] A.E.B. Torres, S.B. Neves, J.C.N. Abreu, C.L. Cavalcante, D.M. Ruthven, Braz. J. Chem. Eng. 18, 121 (2001)

[6] T. Akahori, M. Niinomi, Mater. Sci. Eng. A 243, 237 (1998)

[7] P.J. Aragon, S.F. Hulbert, J. Biomed. Mater. Res. 6, 155 (1972)

[8] M.A. Khan, R.L. Williams, D.F. Williams, Biomaterials 17, 2117 (1996)

[9] M. Long, H.J. Rack, Biomaterials 19, 1621 (1998).

[10] S. Roessler, R. Zimmermann, D. Scharrnweber, C. Werner, H. Worch, Colloid. Surf. B 26, 387 (2002)

[11] D.M. Brunette, P. Tengvall, M. Textor, P. Thomsen, Titanium in Medicine, Springer, Heidelberg 2001.

[12] J.H. Huang, C.H. Ho, G.P. Yu, Mater. Chem. Phys. 102, 31 (2007)

[13] J. Musil, Surf. Coat. Technol. 125, 322 (2000).

[14] S. Veprek, M. Jilek, Pure Appl. Chem. 74, 475 (2002)
[15] W. Herr, E. Broszeit, Surf. Coat. Technol. 97, 335 (1997).

[16] P.H. Mayrhofer, C. Mitterer. Surf. Coat. Technol. 133-134, 131 (2000).

[17] S. Mändl, Materials 2, 1341 (2009).

[18] A. Anders, Surf. Coat. Technol. 156, 3 (2002)

[19] D.J.W. Mous, A. Gottdang, R.V.D. Broek, R.G. Haitsma, Nucl. Instrum. Methods. B 99, 697 (1995)

[20] N. Fairely, CasaXPS Manual 2.3.15, Casa Software Ltd.

[21] D.A. Shirley, Phys. Rev. B 5, 4709 (1972)

[22] B.D. Cullity, S.R. Stock, Elements of X-ray Diffraction, 3rd ed., Prentice Hall, Bellingham 2001.

[23] H. Jiménez, E. Restrepo, A. Devia, Surf. Coat. Technol. 201, 1594 (2006)

[24] I.M. Ismail, B. Abdallah, M.A. Kharroub, O. Mrad, Nucl. Instrum. Methods B 271, 102 (2012)

[25] Y.X. Leng, J.Y. Chen, Z.M. Zeng, X.B. Tian, P. Yang, N. Huang, Z.R. Zhou, P.K. Chu, Thin Solid Films 377-378, 573 (2000).

[26] X. Lui, C. Ding, Biomaterials 23, 4065 (2002)

[27] M.Y.P. Costa, M.O.H. Cioffi, H.J.C. Voorwald, V.A. Guimaraes, Tribol. Int. 43, 2196 (2010)

[28] W.C. Clem, V.V. Konovalov, S. Chowdhury, Y.K. Vohra, S.A. Catledge, S.L. Bellis, J. Biomed. Mater. Res. A 76, 279 (2006)

[29] W. Pawlak, B. Wendler, J. Achiev. Mater. Manufactur. Eng. 37, 660 (2009).

[30] J.E. Alfonso, J. Torres, J.F. Marco, Braz. J. Phys. 36, 994 (2006)

[31] I. Milosev, H.-H. Strehblow, B. Navinsek, M. Metikos-Hukovic, Surf. Inter. Anal. 23, 529 (1995)

[32] A. Glaser, S. Surnev, F.P. Netzer, N. Fateh, G.A. Fontalvo, C. Mitterer, Surf. Sci. 601, 1153 (2007)

[33] R.N.S. Sodhi, A. Weninger, J.E. Davis, K. Sreenivas, J. Vac. Sci. Technol. A 9, 1329 (1991)

[34] N.R. Armstrong, R.K. Quinn, Surf. Sci. 67, 451 (1977)

[35] I. Milosev, M. Metikos-Hukovic, H.H. Strehblow, Biomaterials 21, 2103 (2000)

[36] Y.Z Liu, X.T Zu, C. Li, S.Y Qiu, X.Q. Huang, L.M. Wang, Corros. Sci. 49, 1069 (2007)

[37] M. Scrocco, Chem. Phys. Lett. 61, 453 (1979).

[38] C. Rao, D.D. Sarma, S. Vasudevan, M.S. Hegde, Proc. R. Soc. Lond. A 67, 239 (1979)

[39] C.R. Brundle, Surf. Sci. 52, 426 (1975).

[40] M. Pham, T. Zyganow, I. Matz, W. Reuther, H. Oswald, S. Richter, E. Wieser, Thin Solid Films 310, 251 (1997)

[41] S. Surnev, M.G. Ramsey, F.P. Netzer, Prog. Surf. Sci. 73, 117 (2003)

[42] M. Petukhov, G. Andrea Rizzi, G. Granozzi, Surf. Sci. 490, 376 (2001). 